\title{
"Woman Is The Nigger Of The World". Una aproximación a la ruta contracultural de Lennon-Ono
}

\section{"Woman is the Nigger of the World". An Approach to The Countercultural Path Lennon-Ono}

\author{
Tirso Molinari ${ }^{1}$ \\ Universidad de Lima \\ María Isabel Ginocchio ${ }^{2}$ \\ Universidad Nacional Mayor de San Marcos
}

\begin{abstract}
Es que pensar con la ayuda de las metáforas no es una actividad por la que uno deba disculparse, a menos que tengamos que disculparnos por ser humanos, estar vivos y vivir entre humanos.
\end{abstract}

Zygmunt Bauman

\section{RESUMEN}

Se pretende un acercamiento desde la sociología interaccionista, así como desde la lingüística cognitiva, a las particularidades de la posición contracultural tanto estética-popular como política de John Lennon y Yoko Ono en base a la reivindicación que combina metafóricamente, a su vez, el feminismo y la lucha contra el racismo y se anticipa, a inicios e la década de 1970, a concepciones expertas desde las ciencias sociales, principalmente latinoamericanas, que a partir de inicios de la década de 1990 sistematizan enfoques que correlacionan el racismo y lo étnico con el patriarcalismo desde perspectivas teórico-críticas básicamente ligadas a los estudios poscoloniales, a la denominada colonialidad del poder y a las investigaciones sobre la subalternidad.

\section{Palabras clave:}

Contracultura / Racismo / Patriarcalismo / Feminismo / Subalternidad / Poder / Discurso / Metáfora

\section{ABSTRACT}

An approach is intended from the interactionist sociology, as well as the cognitive linguistics, to J. Lennon and Y. Ono's both aesthetically-popular and political countercultural position particularities, based on the claim that combines simultaneously feminism and the struggle against racism in a metaphorical way, and in the early 70s, it is anticipated to expert views from the social sciences, mainly Latin American ones, that systematise approaches, from the early 90s, where racism and ethnicity with patriarchy are correlated from ethnic-critical theoretical perspectives basically linked to postcolonial studies, the so-called coloniality of power and researches into subalternity.

\section{Keywords:}

Counterculture / Racism / Patriarchy / Feminism / Subalternity / Power / Discourse / Metaphor

1 Tirso Molinari es doctor en Ciencias Sociales-Historia (UNMSM), magíster en Sociología-PUCP, magíster en Historia-PUCP, licenciado en Sociología-UNMSM, docente asociado-ordinario de la Universidad de Lima, docente principal de la UNMSM. Fue docente invitado en la Maestría de Estudios Iberoamericanos de la Universidad de Salamanca-España.

2 María Isabel Ginocchio es magíster en Lingüística-UNMSM, licenciada en Lingüística-UNMSM, docente principal de la UNMSM, investigadora del Instituto de Investigaciones Lingüísticas de la Facultad de Letras y Ciencias Humanas-UNMSM. 
${ }^{\mathrm{m}} \mathrm{n}$ los relatos sociológicos hegemónicos más recientes en el Perú, parcialmente en América Latina, es la propuesta de Aníbal Quijano la prevalente y esta corresponde a la denominada colonialidad del poder, propuesta que Quijano va paulatinamente construyendo, principalmente desde 1990, y luego de todo un corte teórico-epistemológico, con la denominada teoría de la dependencia.

Corte que, en lo esencial, y siguiendo el riguroso estudio de César Germaná (2009a), se inicia y se desarrolla desde diversos artículos, donde destacan los siguientes: "Notas sobre los problemas de investigación social en América Latina", "Colonialidad y modernidad-racionalidad", "Colonialidad del poder, eurocentrismo y América Latina", "Colonialidad del poder, globalización y democracia", "Colonialidad del poder, cultura y conocimiento en América Latina", "Notas sobre raza y democracia en los países andinos", "¡Que tal raza!", "Colonialidad del poder y clasificación social" y, ya en 2006, "Don Quijote y los molinos de viento en América Latina".

Asimismo, esta propuesta teórico -epistemológica tiene en el medio académico universitario peruano, además de César Germaná, a otros importantes adeptos, como son Julio Mejía (2009a) y Carolina Ortiz (2004), entre los más destacados.

Pues bien, en dicha propuesta sociológica se pone de relieve la relación entre eurocentrismo, modernidad, capitalismo y racismo, todo eso ligándose, a su vez, a diferentes formas de opresión social en el ejercicio del poder que incluye intensamente a las relaciones de género-patriarcalismo y étnicas, como bien sintetiza Carolina Ortiz en su artículo "Género, colonialidad del poder, conocimiento y las políticas de igualdad hoy" (2011).

Entonces, nos estamos refiriendo a construcciones sociológicas recientes y que incluyen en el ámbito latinoamericano a varios autores como Walter Mignolo (2007) y Boaventura de Souza Santos (2006), destacados teóricos e investigadores ubicados, en lo fundamental, en este horizonte sociológico, así como a un conjunto de autores(principalmente antropólogos e historiadores) tanto norteamericanos, europeos y latinoamericanos, aunque, en este caso, solo básicamente incluidos en tal horizonte, y que han venido construyendo, también recientemente, los denominados estudios sobre la subalternidad (Sandoval 2009) y que, a su vez, corresponden a estudios que se van definiendo desde la década 1990 y, sobre todo, post años 2000.

Es decir, la relación entre racismo y género, por ejemplo, presente en las temáticas centrales de todo aquel horizonte teórico-académico y paradigmático tiene un tiempo que no va más allá de veinte a veinticinco años; sin embargo, dado que, sociológicamente, nada se ha dicho en nuestro medio, por la prevalencia aún de sutiles positivismos y de poco sutiles reduccionismos 0 , dicho con mayor precisión, desde cierta prevalencia de tecnorracionalismos, tanto cognoscitivos como metodológicos (Molinari, 2011) y, sobre todo, valorando las consideraciones de Zygmunt Bauman (2014) sobre la experiencia humana y su condición dialéctica, así como la imprescindible vinculación entre la sociología y el arte, en aras del énfasis en la subjetividad e intersubjetividad, nos acercaremos a un singular panorama artístico-social y político-crítico, construido desde el "conocimiento ordinario" (Mafessoli, 1993)

Todo ello estaba siendo reflejado, en el contexto de inicios de la década de 1970, en muchas obras de diferente corte artístico, indudablemente, bajo el influjo de las tendencias feministas y del movimiento de los derechos civiles, especialmente por los derechos de los afroamericanos, en sus versiones más radicalizadas, donde se hará referencia a un disco de John Lennon y la Plastic Ono Band, que producen, específicamente, en 1972.

Se trata del disco Some Time in New York (Capitol Music Label-New York), un disco agudamente iconoclasta y transgresivo, donde, precisamente, el tema principal es "La mujer es el negro del mundo" (Lennon-Ono).

Fue un tema compuesto, entendiéndose, desde el contexto e impacto de los movimientos anticolonialistas, así como antiimperialistas, bajo la perspectiva de movimientos en los que, como se sabe, Lennon y Ono participan con performances de protesta pacifistas bastante publicitadas, de los movimientos afrorradicales antirracistas en Estados Unidos, de los movimientos feministas y la abierta crítica al capitalismo que caracterizaba a Lennon, en esos años, tal como ya se advertía en un disco anterior: "Working Class Hero" ("Héroe de la clase trabajadora").

Se trataba, entonces, de una canción cuya base metafórica alude directamente a la particular condición oprimida de la mujer en relación al otro gran oprimido histórico: el "negro". Contundente metáfora cuya relación mujer-negro constituye todo un mensaje pionero que se anticipa pero que, a su vez, se inserta en aquel horizonte que posteriormente, y varias décadas después, se denominará, en el ámbito ya de las ciencias sociales, colonialidad del podery, paralelamente, subalternidad.

Asimismo, dicho disco reivindica, en su carátula e iconográficamente, al movimiento gay (aún temprano), al rechazo a la invasión a Vietnam, así como a un personaje emblemático como Angela Davis, la más importante activista del Black Power y en esos momentos encarcelada, a quien, además, le dedican una de las principales canciones de aquella producción musical del pop-rock contestatario, quizás la de mayor condición paradigmática-contracultural en el legado artístico de Lennon-Ono.

Veamos, al respecto, la letra de aquella canción tan contundente y, a su vez, tan emblemática en cuanto lo concerniente a esa aguda metáfora ("mujer-negro") que, desde el arte popular y el "conocimiento ordinario", y así cargada de experiencias humanas e influencias político-contestatarias, se insertará, décadas después, al horizonte de la colonialidad del poder y también a la perspectiva teórico-crítica de la subalternidad. Asimismo, y desde una aproximación lingüística cognitiva, se hará una reflexión desde la cual se intentará correlacionar la metáfora y el discurso de dicha canción, resaltándose ahí su aguda condición contracultural. 


\section{Título: "Woman is the nigger of the world"}

\section{Autores: John Lennon y Yoko Ono}

"La mujer es el negro del mundo

Claro que lo es (Sí, ella lo es)... Piensa en eso

La mujer es el negro del mundo

Claro que lo es (Sí, ella lo es)... Haz algo sobre ello

La hacemos pintarse la cara y bailar

Si no se nos hace esclava, decimos que no nos ama

Si ella es auténtica, decimos que está tratando de ser un hombre

Mientras la reprendemos, fingimos fuertemente que está por debajo de nosotros

La mujer es el negro del mundo...

Claro que lo es (Sí, ella lo es)

Si no me crees, mira a la que está contigo

La mujer es la esclava para el esclavo

Oh sí... si me crees, es mejor que lo grites, que lo denuncies

La hacemos parir y criar a nuestros hijos

Y luego la dejamos aplastada (exprimida, sin fuerzas, etc.) para que se convierta en una vieja gorda y clueca

Le decimos que nuestra casa es el único lugar donde ella debe estar

Y luego nos quejamos de que es muy poco mundana para ser nuestra amiga

Oh, ahora la mujer es el negro del mundo... isí!

La mujer es la esclava para el esclavo

¡Sí!

La insultamos a diario en la TV

Y nos preguntamos por qué no tiene agallas ni confianza

La mujer es la esclava para el esclavo

¡Sí!

Cuando es joven matamos su voluntad de ser libre

Mientras la maltratamos por tonta, la maltratamos por ser tontos

¡Sí!

Oh, ahora la mujer es el negro del mundo... iOh sí!

Si no me crees, mira a la que está contigo

La mujer es la esclava para el esclavo." 


\section{De la metáfora al discurso: "The Woman is the nigger of the world"}

Esta metáfora, que como ya indicáramos, pertenece al título de una canción, acuñada por John Lennon (1940-1980) y Yoko Ono (1933) a principios de la década del setenta del siglo pasado, responde a muchas interpretaciones, todas ellas relacionadas con el cambio ideológico y político que se estaba generando en gran parte de la sociedad occidental $-\mathrm{y}$, en casos aislados, en parte de la sociedad oriental- en relación al rol de la mujer. No obstante, esta frase reviste cierto reclamo que intentan expresar los autores para, además de criticar la situación de la desigualdad de roles dentro de la sociedad, hacer una audaz comparación del rol de la mujer con la que tenía la población afrodescendiente hasta la mitad del siglo XIX, la de un ser esclavizado por el grupo social dominante y bajo el contexto colonial y neocolonial histórico-eurocéntrico.

Si se tiene el objetivo de descubrir lo que se encuentra detrás de esa metáfora, en primer lugar, se tiene que recurrir a la lingüística cognitiva, marco teórico que exige, entre otros conceptos que evocan la interdisciplinariedad donde el punto fundamental es la consideración de las habilidades cognitivas, la aproximación del análisis de la consideración del sujeto hablante y la integración del lenguaje con las habilidades cognitivas (Gonzales, 2016). Para el análisis de esta frase es necesario recurrir a la teoría de la metáfora conceptual, donde se indica un conjunto de proyecciones entre los elementos del dominio fuente y el dominio meta, además de un conjunto de inferencias que resultan posibles gracias a esa asociación, llamadas correspondencias ontológicas (Soriano, 2012). A su vez, esta metáfora requiere el aporte de la teoría de la metáfora de la Gran Cadena del Ser, un modelo cultural que permite la determinación de los atributos y el comportamiento de los entes naturales (Lakoff y Turner, 1989 en Moreno Lara, 2004), donde la jerarquía "humanos" se ajusta a nuestro análisis.

En el mundo occidental —para fines del caso a analizar, en Estados Unidos- la construcción de un ser con ciertas características saltantes puede rastrearse de manera diacrónica y sincrónica en la literatura y en la vida cotidiana, y ha dado cuenta de las ansiedades y repulsiones que ciertos actores sociales inspiran en las representaciones sociales de la época (Pérez, 2008). En este caso, el afrodescendiente, durante los siglos XVII al XX, según el discurso de la época, era un ser considerado "inferior", además de carente de derechos, relacionado -al menos antes de la irrupción en la escena del luchador social por los derechos civiles, Martin Luther King, así como Malcom X, y los movimientos sociales que lideraron- con el prototipo de "esclavo" que imperaba hasta mediados del siglo XIX, cuando en EE.UU. se abolió la esclavitud, gracias, entre otras acciones, a la política implantada por el expresidente Abraham Lincoln. Ese criterio de calificación, según Pérez (2008), es una "distinta forma de (calificar) al otro", a quien los procedimientos de retorización construyen como una alternativa quizá radical que, al final, queda proscrito de lo humano.

Teniendo en cuenta este análisis histórico-comparativo, la metáfora, como un procedimiento cognitivo, va a permitir conceptualizar y nombrar a una persona como un ser carente de libertad, donde se le adjudicará propiedades como "esclavo", "sometido", "títere" y "tonto", entre otros calificativos de índole peyorativa. Este procedimiento se ha logrado acentuar con el pasar de las décadas, lo que permite que, desde la década de los setenta, se tome un ejemplo particular como motivo de análisis lingüístico y social, "Woman is the nigger of the World", donde comienza a vislumbrarse un proceso metafórico, donde a la mujer se le adjudicará las propiedades implícitas que tiene la expresión nigger ${ }^{3}$, un término con alta carga peyorativa, donde, además de caracterizar a un afrodescendiente -especialmente anglohablante- contiene propiedades como "esclavo" y "animal" —pues, hasta antes de mediados del siglo XIX, se tenía dudas de considerar como personas a los miembros de ese grupo social proveniente del continente africano.

Hay un punto que se debe tener muy en cuenta antes del análisis de esa metáfora, el cual es la intención con la que fue dicha. Los últimos años de la década de los sesenta, así como a lo largo de la década del setenta del siglo pasado, se experimentaron, sobre todo entre las juventudes, grandes innovaciones ideológicas, políticas y sociales ${ }^{4}$, haciéndose esto masivo e intenso, de manera paulatina, entre los actores de los grupos sociales que poseían en común una concepción marcadamente contracultural.

Así, John Lennon y Yoko Ono, con esa metáfora y, a su vez, emblemática canción, asumían la protesta contra la opresión social de la mujer de manera enfática e irónica, rompiendo los esquemas de lo "políticamente correcto" en relación con temas sensibles que concernían al sector más oprimido de la población, independientemente de la procedencia o estrato social. Al establecer una comparación de la

3 En inglés existen tres términos que históricamente han definido al grupo social afrodescendiente: "negro," “nigger” y “black", refiriéndose el primero a la raza; el segundo a la raza y a las consideraciones que se les asignaba, todas ellas peyorativas, referentes a la esclavitud y a su categoría impuesta como seres vivos, y el tercero al color de la piel.

4 A inicios de la década de 1970, en EE.UU. se comenzaba a desarrollar el jipismo, las grandes manifestaciones antibélicas, antirracistas y feministas e, inclusive, multitudinarios y bastante contraculturales conciertos de rock, como el famoso festival Woodstock. 
mujer con la persona afrodescendiente —el llamado "negro"-, utilizando el término con mayor carga peyorativa, no se hacía solamente referencia al color de piel, sino también a la función impuesta que tenían, étnicamente, sus descendientes, y a las características que, a menudo, se le asignaban (alejándolo incluso del prototipo del concepto de "ser humano"); puede considerarse aquello como un llamado frontal de atención al poder hegemónico para superar radicalmente, en aquel contexto, la condición social de la mujer, y lo que pretendía, entre otras exigencias y acciones, era, entonces, superar el estigma de servidumbre del género femenino al biopoder masculino-cotidiano, además de exigir igualdad de condiciones en todas las áreas de la sociedad civil.

En tal sentido, como dispositivo ideológico (al cual enfrentan contraculturalmente Lennon-Ono), Pérez (2008) afirma que el tropo $0^{5}$ habilita la posibilidad de dejar a la persona - para fines de análisis, específicamente la mujer-al margen del contrato social, privarla de derechos humanos y llegar, incluso, a someterla.

Estos procedimientos -retóricos y también ideológicos - resaltan uno de los mayores riesgos en la definición actual de "lo humano", en concordancia con el primer artículo de la Declaración Universal de los Derechos Humanos: la anulación de su libertad.

La composición de Lennon y Ono evoca la creación de una figura literaria que expresa de la manera menos sutil posible el mensaje de lo que se quiso transmitir en aquella época, por lo que se ha de considerar que, además de la función referencial de la metáfora —especialmente usada en el lenguaje poético-, donde se exalta aquello de lo que se habla, evidenciándose, específicamente, en el título de la canción (González, 2014, pp. 36-37, en Ricoeur, 1980), en la cual se halla también una serie de funciones referenciales —en el ámbito poético y cotidiano - divididas en eufemísticas y disfemísticas (González, 2016).

En "Woman is the nigger of the world" se observa la función disfemística, donde se evidencia un mantenimiento e intensificación entre el símbolo (la mujer que sufre opresión) y el referente (el afrodescendiente en condición de esclavitud) (González, 2016), de modo que quede patente su lado más polémico e incómodo, generando una irrupción en la normalidad comuni- cativa arbitrariamente establecida. La metáfora de Lennon y Ono ha llegado a cumplir sus objetivos, pues, como enumera González (2014), en palabras de Juan Díaz Pérez (González, 2014, p. 37, en Díaz Pérez, 2012, pp. 171-173), el disfemismo es el medio por el cual uno se rebela contra lo establecido, suponiendo al mismo tiempo rebelarse contra las reglas del bien decir, denunciar y protestar, evitar la ambigüedad, buscar expresarse de manera irónica y creativa, atentar contra la sensibilidad del oyente, desahogarse expresando frustración y enojo (catarsis) y marcar jerarquía social, pues, al tener una cuasiconstante exposición en los medios de comunicación (González, 2016), estos dos artistas podían darse el lujo contracultural de ser más disfemísticos, por su posición de estrellas masivas, traduciéndose en un mayor nivel de audiencia.

Este procedimiento cognitivo de la metáfora consiste, en principio, en una máquina que produce al otro sera partir del reconocimiento del ser referido, cuya característica principal es la carencia de la libertad y que la diferencia será anulada cuando se nombra y conceptualiza un ser en términos de otro, siendo este proceso un fenómeno del lenguaje y del pensamiento (Pérez, 2008).

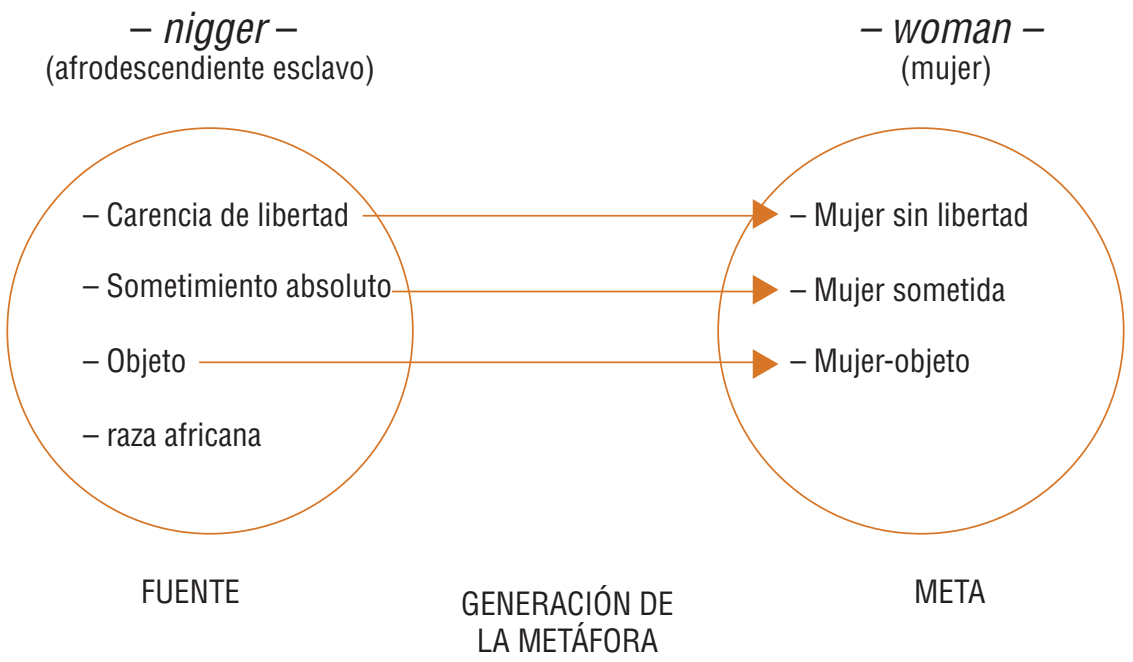

5 Los tropos son figuras de lenguaje, por las cuales se hace tomar a una palabra un significado que no es precisamente el significado propio de esa palabra "[...] Estas figuras son llamadas tropos del griego tropé [...] donde la raíz es trepo, [...], yo giro" ("[...] Ces figures font apelées trope, du grec tropé [...] dont la racine est trepo, [...], je tourne"). Se llaman así porque, cuando se toma una palabra en su sentido figurado, la giramos, por así decirlo, a fin de hacerla significar lo que no significa en el sentido propio (Du Marsais, 1757, p. 14). 
Puede postularse que la generación de esta metáfora con el término "nigger" habría podido generar una variación semántica en el concepto de "mujer" cuando se la quiere calificar en términos de ser alguien "esclava del grupo social dominante" (el género masculino). Además, la utilización de la fuente del término peyorativo para referirse a un afrodescendiente ha podido generar otras metáforas, como la famosa frase del escritor irlandés Roddy Doyle, en su obra The Commitments (1987) "The Irish are the niggers of Europe... An' Dubliners are the niggers of Ireland... An' the northside Dubliners are the niggers $0^{\prime}$ Dublin", intentando reclamar que el pueblo irlandés siempre ha estado en desventaja en cuanto a las libertades con que contaban los segmentos sociales británicos-hegemónicos.

\section{Bibliografía}

Bauman, Z. (2014). ¿Para qué sirve realmente... un sociólogo? Barcelona: Paidós.

De Sousa Santos, B. (2006). Conocer desde el sur. Para una cultura emancipatoria. Lima: UNMSM-CCSS.

DoyLe, R. (1987). The Commitments (The Barrytown Trilogy \#1). Dublin: King Farouk Publishing Ltd.

DoyLE, R. (2017). Roddy Doyle quotes. All Great Quotes [portal web]. Recuperado de http://www.allgreatquotes.com/ roddy_doyle_quotes.shtml

Du Marsais, C. C. (1757). Traité des tropes. Pour servir d'introduction à la rhétorique et à la logique, par Mr. Du Marsais. Leipzig: Chez la veuve Gaspard Fritsch.

GermanÁ, C. (agosto del 2009). Una epistemología otra. La contribución de Aníbal Quijano a la reestructuración de la Sociología en América Latina. Sociológica, Revista del Colegio de Sociólogos del Perú, /(1).

González, D. S. (2014). Una revisión de la teorización sobre la metáfora en el tratado I de La metáfora viva de Paul Ricoeur. Lengua y Habla, (18), 29-38.

González, D. S. (2016). La lingüística cognitiva y su teorización sobre la metáfora conceptual. Principales visiones históricas sobre el fenómeno y caracterización desde los principios cognitivo-funcionales. Saarbrücken: Editorial Académica Española.

Mafessolı, M. (1993). El conocimiento ordinario. México, D. F.: Fondo de Cultura Económica.

Mesía, J. (2009). Sociedad y conocimiento. Los desafíos de la sociología latinoamericana. Lima: UNMSM, Facultad de Ciencias Sociales.

Mesía, J. (2009). Los desarrollos de las ciencias sociales en América Latina. Sociológica, Revista del Colegio de Sociólogos del Perú, /(1), 69-77. Recuperado de http://www.ceapedi.com.ar/imagenes/biblioteca/libros/217.pdf

Mıgnolo, W. (2007). La idea de América Latina. La herida colonial y la opción decolonial. Barcelona: Gedisa.

MolinaRI, T. (2011). Metateoría, sociología y visiones del Perú. Revista de Sociología, XVII(21), 139-145.

Moreno Lara, M. A. (2005). La metáfora conceptual y el lenguaje político periodístico: configuración, interacciones y niveles de descripción [tesis doctoral]. Universidad de La Rioja. Recuperada de https://dialnet.unirioja.es/servlet/ tesis?codigo $=114$

ORTIZ, C. (2004). Procesos de descolonización del imaginario y del conocimiento en América Latina. Lima: UNMSM, CCSS.

ORTIZ, C. (2011). Género, colonialidad del poder, conocimiento y políticas de igualdad hoy. Revista de Sociología, XVII(21). 
Pérez, E. (2012). Metáfora y deshumanización. En G. E. Müller, L. Miñones y V. Barbeito (comps.), Estudios de lingüística cognitiva (pp. 347-353). Mendoza: EDIUNC, Universidad Nacional de Cuyo.

Quisano, A. (1990). Notas sobre los problemas de la investigación social en América Latina. Revista de Sociología, (6).

Quisano, A. (1991). Colonialidad, modernidad/racionalidad. Revista del Instituto Indigenista del Perú, (29).

QuiJano, A. (2000). Colonialidad del poder, eurocentrismo y América Latina. En E. Lander (ed.), Colonialidad del saber: eurocentrismo y ciencias sociales (pp. 122-151). Buenos Aires: Clacso-Unesco. Recuperado de http://bibliotecavirtual.clacso.org.ar/clacso/sur-sur/20100708034410/lander.pdf

Quisano, A. (2000). Colonialidad del poder, globalización y democracia. En V. AA., Tendencias básicas de nuestra época. Globalización y democracia (pp. 25-61). Caracas: Instituto de Estudios Diplomáticos e Internacionales Pedro Gual.

Quisano, A. (2001). Colonialidad del poder, cultura y conocimiento en América Latina. En W. Mignolo (ed.), Capitalismo y geopolítica del conocimiento. El eurocentrismo y la filosofía de la liberación en el debate intelectual contemporáneo. Buenos Aires: Signo.

Quijano, A. (2003). Notas sobre raza y democracia en los países andinos. Revista Venezolana de Economía y Ciencias Sociales, (9).

Quisano, A. (2000). ¡Qué tal raza! Revista Venezolana de Economía y Ciencias Sociales, (6).

Quisano, A. (2000). Colonialidad del poder y clasificación social. Journal of World-Sistems Research, (6).

Quisano, A. (2006). Don Quijote y los molinos de viento en América Latina. Revista Investigaciones Sociales, (16).

SAndoval, P. (ed.). (2009). Repensando la subalternidad. Miradas críticas desde/sobre América Latina. Lima: IEP-SEPHIS.

SoRIAno, C. (2012). La metáfora conceptual. En I. Ibarretxe-Antuñano y J. Valenzuela (eds.), Lingüística Cognitiva (pp. 97-121). Barcelona: Anthropos. Recuperado de https://www.textosenlinea.com.ar/academicos/Soriano\%20-\%20 La\%20metafora\%20conceptual.PDF 
Anexo

Consideraciones propuestas por Bauman en el libro citado, sobre las relaciones entre la experiencia humana, la sociología y el arte

"La sociología como conversación con la experiencia humana [...] quiero decir, tanto erfahrung como erlebnisse, ambos términos generados por el interfaz entre persona y mundo, que los germanófonos distinguen y que los anglófonos, debido a la falta de sustantivos diferenciados, juntan bajo la única noción de experiencia. Erfahrung es lo que me ocurre a mí cuando interactúo con el mundo. Erlebnisse es aquello que experimento en el curso de ese encuentro, el producto conjunto de mi percepción de lo que sucede, y mi esfuerzo por absorberlo y hacerlo intelegible. Erfahrung puede, y requiere, tener un estatus de objetividad (supra 0 interpersonalidad), mientras que erlebnisse es clara y abiertamente subjetivo". (pp. 22-23)

"La gente va por el mundo obedeciendo su rutina cotidiana y resignada por adelantado a la imposibilidad de cambiarla y, sobre todo, convencida de la irrelevancia y de la ineficacia de sus propios actos o persuadida de que no debe actuar.

Al margen de la crítica de la visión que subyace en este quietismo la variedad sociológica de la conversación dedicada a la expansión de la libertad individual y del potencial colectivo de la humanidad tiene por objetivo revelar y descubrir los elementos que, por ser engañosos o crear confusión, proporcionan una base para el tipo de planteamientos que sostienen y estimulan continuamente las actitudes quietistas. La relativización aporta ambas partes del encuentro erfahrungen/erlebnisse: es la dialéctica de su interacción la que constituye el objetivo último de la conversación". (pp. 25-26)

"En su libro El telón, Milán Kundera escribe sobre Miguel de Cervantes: 'Un telón mágico, tejido de leyendas colgaba ante el mundo. Cervantes envió de viaje a Don Quijote y rasgó el telón. El mundo se abrió ante el caballero andante en toda la desnudez cómica de su prosa'. Kundera propone que el acto de rasgar el telón de los prejuicios fue el nacimiento de las artes modernas". (p. 31)

"Pero la imagen del telón mágico y su rasgadura me sorprende por ser eminentemente apropiada para describirla labor de los que siguieron la vocación sociológica". (p. 32)

"Pero yo diría que la literatura y la sociología son hermanas: su relación es una mezcla de rivalidad y apoyo mutuo [....] ambas hermanas persiguen, al fin y al cabo, lo mismo: rasgar el telón". (p. 33)

"Nos guste o no, los ámbitos de la ciencia y de la ficción [...] se encuentran y se enfrentan mutuamente en un mismo terreno: la experiencia humana”. (p. 35)

"La falacia cartesiana: la presunción tácita de la yuxtaposición exacta entre sujeto y objeto del estatus de los investigadores y de aquello que es investigado [...] el quid de la cuestión es, de forma resumida, el siguiente: la verdad producida con los estándares de la ciencia se basa en la aplicabilidad genuina 0 asumida de la dicotomía cartesiana entre sujeto y objeto. En otras palabras, esa verdad es válida, por tanto, en aquellas ciencias humanas en las que su objeto, los humanos, son despojados de su subjetividad. Como si no hubiese habido ya intentos de despojarlos de ella, como en Auschwitz y los gulags. El elemento perturbador, indomable, irreductible, que surge entre la verdad natural científica y la social-científica es, precisamente, la subjetividad humana y la consiguiente identidad, no la oposición ontológica ni epistemológica entre los estatus de los investigadores y de aquellos a quienes investigan". (pp. 39-40)

"Las artes son distintas de las ciencias (incluso en su variedad social) porque tratan de captar la verdad de sus objetos en su vida real no en condiciones artificialmente simplificadas: reducidas, descontaminadas y desinfectadas, por el ideal experimental, sobre todo porque están obligadas y condenadas a tratar a sus sujetos como objetos, lo que implica la identidad entre su estatus y el de los sujetos; y ello por el hecho de que, a diferencia de los neutrones, los leucocitos y los estratos geológicos, sus objetos son criaturas que eligen y los procedimientos de la ciencia social influyen en sus decisiones. Esta circunstancia, en sí misma, constituye un límite insuperable para cualquier soñador científico-social de alcanzar la autoridad y el prestigio del estatus del científico natural. Mientras sigan tratando de emular el ejemplo de la ciencia natural, mientras den la espalda a los escritores y artistas [...] los sueños de madurez de los científicos sociales para alcanzar el estatus de las ciencias naturales son tan descabellados y estúpidos como suicidas para la disciplina social-científica". (pp. 40 y 41)

"La sociología es una actividad crítica en la medida en que lleva a cabo una continua deconstrucción derridiana de la percepción de la realidad social" (p. 41). 